\title{
PENGARUH PEMBERDAYAAN ZAKAT DALAM MENINGKATKAN MODAL MANUSIA DAN KESEJAHTERAAN MASYARAKAT MISKIN
}

\author{
Maimun Sholeh \\ Universitas Negeri Yogyakarta, Indonesia \\ maimunsholeh@uny.ac.id
}

\begin{abstract}
Abstrak: Penelitian ini bertujuan untuk mengetahui pengaruh Modal manusia dan pemberdayaan terhadap kesejahteraan masyarakat miskin khususnya masyarakat miskin yang diberdayakan oleh lembaga zakat sehingga bisa dibuat strategi yang tepat untuk meningkatkan kesehteraan mereka. Penelitian ini merupakan studi eksplanatori dilakukan dengan menggunakan pendekatan SEM (Structural Equation Model). Anggota sampel ditentukan dengan metode non-probability sampling khususnya dengan purposive sampling. Data dikumpulkan secara cross section dianalisis secara kuantitatif. Hasil penelitian menunjukkan bahwa baik modal manusia maupun pemberdayaan berpengaruh terhadap kesejahteraan masyarakat miskin khususnya masyarakat penerima pemberdayaan zakat.
\end{abstract}

Kata kunci: Zakat, Modal Manusia, Kesejahteraan Masyarakat Miskin

\section{THE EFFECT OF ZAKAT EMPOWERMENT IN IMPROVING HUMAN CAPITAL AND THE WELL-BEING OF THE POOR COMMUNITY}

\begin{abstract}
This study aims to determine the effect of human capital and empowerment on the welfare of the poor, especially the poor, who are empowered by zakat institutions so that the right strategy can be made to improve their health. This research is a descriptive study conducted using the SEM (Structural Equation Model) approach. The sample members are determined by the non-probability sampling method, especially by purposive sampling. Data were collected by cross-section and analyzed quantitatively. The results showed that both human capital and empowerment affected the welfare of the poor, especially those who received zakat empowerment.
\end{abstract}

Keywords: Zakat, Human Capital, Welfare of the Poor

\section{PENDAHULUAN}

Sampai saat ini kemiskinan menjadi masalah penting bagi setiap Negara baik di Negara berkembang maupun maju, tidak terkecuali Indonesia. Bahkan kemiskinan menjadi fokus utama di beberapa negara baik negara maju maupun negara berkembang (Lingga, 2018). Kemiskinan merupakan tantangan besar yang selalu harus dihadapi oleh setiap Negara dari tahun ke tahun. Kemiskinan masih dianggap suatu masalah yang besar sebab jika seseorang miskin berarti ia membutuhkan perjuangan yang lebih keras untuk mendapatkan sesuatu hal dalam waktu dekat dan belum terpikirkan untuk apa yang terjadi esok hari. Hal tersebut mengakibatkan masalah umum dan menyebabkan banyak kerugian seperti terjadinya ketimpangan pendapatan, kejahatan dan distorsi (Solikatun et al., 2014). Selain itu mendorong terjadinya kerusakan, pengangguran dan sebagainya.

World Bank (World Bank, 2000) mendefiniskan kemiskinan sebagai kehilangan kesejahteraan (deprivation of well being). Kehilangan kesejahteraan berarti tidak terpenuhinya 
kebutuhan minimal dari standar hidup tertentu. Untuk mengetahui perubahan kesejahteraan tersebut, perlu memperhatikan beberapa kriteria sebagai berikut: kependudukan, kesehatan dan gizi, pendidikan, ketenagakerjaan, taraf dan pola konsumsi, perumahan dan lingkungan, kemiskinan, serta sosial lainnya (Badan Pusat Statistik, 2019). Apabila kriteria-kriteria tersebut mengalami peningkatan yang positif maka kesejahteraan suatu penduduk pun membaik, berlaku sebaliknya, apabila kriteria-kriteria tersebut mengalami perubahan negatif maka kesejahteraan pun menurun.

Indonesia sebagai salah satu Negara berkembang tentu menghadapi perliknya permasalah pengentasan kemiskinan. Walaupun berbagai program pengentasan kemiskinan gencar dilaksanakan, namun secara umum, angka gini rasio dan angka kemiskinan cenderung masih tinggi (Widyastuti, 2018). Pada lima tahun terakhir, gini rasio Indonesia hampir mendekati setengah, yaitu 0,41; 0,40; 0,39; 0,39; dan 0,38 (Indonesia Investments, 2017)(Situmorang, 2020). Walaupun gini rasio tersebut mengalami penurunan, namun masih dianggap tinggi. Hal tersebut menunjukkan bahwa distribusi pendapatan di Indonesia masih belum merata sehingga jarak antara penduduk kaya dengan penduduk miskin memiliki ketimpangan yang masih tinggi. Dengan seperti itu, dapat dikatakan bahwa masih banyak penduduk miskin di Indonesia.

Kemiskinan erat hubungannya dengan modal manusia (human capital), jika modal manusia tersebut postif maka akan membawa kebahagiaan atau kekayaan tetapi jika sebaliknya modal manusia tersebut negatif maka akan membawa kemiskinan (Khan et al., 2016). Modal manusia tersebut antara lain tingkat pendidikan, kesehatan dan umur panjang, serta pendapatan (Becker, 1995). Pendidikan merupakan komponen terpenting dalam pengentasan kemiskinan sehingga dapat dikatakan sebagai pintu masuk utama untuk mengatasi kemiskinan karena melalui pendidikan seseorang akan dapat bersaing di dunia kerja (Tilak, 2002).

Suatu masyarakat dikatakan sejahtera atau berdaya jika masyarakat yang awalnya tidak mampu memenuhi kebutuhan hidupnya secara bermartabat atau tidak mempunyai gagasan menjadi masyarakat yang mampu memenuhi tidak hanya kebutuhan kebutuhan pokok tetapi juga mampu melakukan alternatif pilihan gagasan atau tindakan agar terwujudnya keinginan yang diharapkan. Keberdayaan meliputi keberdayaan berpikir, bertindak dan mengendalikan apa yang mereka lakukan. Kesejahteraan dan keberdayaan masyarakat merupakan suatu kondisi yang dialami oleh masyarakat yang ditandai dengan kemampuan memikirkan, memutuskan serta melakukan sesuatu yang dipandang tepat demi mencapai pemecahan masalah-masalah yang dihadapi dengan mempergunakan daya/kemampuan yang dimiliki. Untuk meningkatkan kesejahteraan dan keberdayaan maka pemberdayaan masyarakat perlu dilakukan. Paradigma baru pemberdayaan adalah menempatkan masyarakat sebagai pelaku utama pembangunan dan lebih bersifat memberdayakan masyarakat. Salah satu yang harus diperhatikan dalam proses pemberdayaan masyarakat adalah keterlibatan masyarakat sasaran dalam pemanfaatan potensi sumberdaya yang dimilikinya secara optimal agar dapat menolong dirinya sendiri (mandiri). 
Kesejahteraan masyarakat memiliki korelasi dengan ketersediaan faktor modal manusia dan kemampuan pelaku pemberdayaan, perencanaan partisipatif serta proses pemberdayaan yang melibatkan masyarakat secara efektif. Pemberdayaan masyarakat dapat pula dilakukan dengan berbasis Zakat, dimana Strategi demikian disebut Strategi Societal Welfare (Nasrullah, 2018). Pendekatan pemberdayaan masyarakat berbasis zakat bertujuan untuk menginternalisasikan tujuan zakat bagi perubahan kesejahteraan masyarakat miskin (duafa). Zakat bukan hanya ibadah maliyah yang hanya karitatif, melainkan juga digunakan untuk mendorong terwujudnya perubahan kesejahteraan masyarakat duafa sehingga memiliki daya untuk berusaha dan mandiri sehingga dapat meningkatkan pendapatan agar terjadi peningkatan kesejahteraan secara materi maupun immateri sehingga mereka memiliki kepercayaan sehingga dapat mandiri serta menghindari sifat ketergantungan.

\section{METODE}

Jenis penelitian ini adalah penelitian deskriptif kuantitatif. Penelitian ini menggunakan data primer yang bersumber pada kuesioner dan wawancara terstruktur terhadap responden dengan menggunakan daftar pertanyaan yang telah dipersiapkan sebelumnya, dimana mustahiq penerima manfaat pemberdayaan sebagai anggota sampel. Anggota sampel ditentukan dengan metode nonprobability sampling khususnya dengan purposive sampling. Jumlah sampel diambil $10 \%$ dari populasi agar diperoleh sampel dengan tingkat kepercayaan yang sesuai (Nurudin et al., 2014).

Dalam studi ini yang menjadi obyek penelitian adalah modal dasar manusia, pemberdayaan dan keberdayaan masyarakat miskin. Sementara itu, yang menjadi subyek penelitian adalah mustahiq yang ada di wilayah yogyakarta dan yang mendapat pemberdayaan dari Lembaga Amil Zakat. Analisis data dalam penelitian ini adalah Structural Equation Modeling (SEM). SEM digunakan dalam penelitian ini karena SEM dapat menjawab pertanyaan penelitian yang bersifal regresif maupun dimensional.

Model pengukuran faktor pemberdayaan mengacu pada Fujikake (Fujikake, 2008), dibentuk melalui 5 (lima) indikator yaitu penyadaran, pemahaman, pemanfaatan, penggunaan keterampilan, dan berkesinambungan yang dapat dikonversi menjadi persamaan berikut:

$$
\begin{aligned}
& \mathrm{X} 11=\lambda 1.1 \xi 4+\varepsilon 41 \\
& \mathrm{X} 12=\lambda 1.2 \xi 4+\varepsilon 42 \\
& \mathrm{X} 13=\lambda 1.3 \xi 4+\varepsilon 43 \\
& \mathrm{X} 14=\lambda 1.4 \xi 4+\varepsilon 44 \\
& \mathrm{X} 15=\lambda 1.5 \xi 4+\varepsilon 45 .
\end{aligned}
$$

Keterangan :

$\xi 4=$ Pemberdayaan mustahiq

$\lambda=$ Hubungan antara variable laten terhadap indikator

$\mathrm{X} 11$ = Penyadaran 


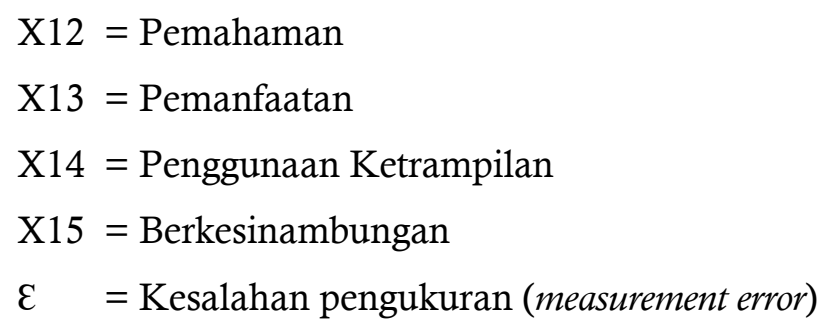

Model pengukuran konstruk Modal Manusia mengacu pada hasil penelitian Todaro Dan Smith (Todaro, 2000) dibentuk melalui 5 (lima) yaitu pendidikan, kesehatan, kemampuan untuk berhubungan satu dengan yang lain, pendapatan, dan kepemilikan aset yang dapat dikonversi menjadi persamaan berikut:

$$
\begin{aligned}
\mathrm{Y} 11 & =\lambda 1.1 \xi 2+\varepsilon 21 \\
\mathrm{Y} 12 & =\lambda 1.2 \xi 2+\varepsilon 22 \\
\mathrm{Y} 13 & =\lambda 1.3 \xi 2+\varepsilon 23 \\
\mathrm{Y} 14 & =\lambda 1.4 \xi 2+\varepsilon 24 \\
\mathrm{Y} 15 & =\lambda 1.5 \xi 2+\varepsilon 25
\end{aligned}
$$

Keterangan :

$\xi 2=$ Modal Manusia mustahiq

$\lambda=$ Hubungan antara variable laten terhadap indicator

Y11 = Pendidikan

$\mathrm{Y} 12=$ Kesehatan

Y13 = Kemampuan Untuk Berhubungan Satu Sama Lain

$\mathrm{Y} 14=$ Pendapatan

$\mathrm{Y} 15=$ Pemilikan aset

$\varepsilon \quad=$ Kesalahan pengukuran (measurement error)

Model pengukuran keberdayaan dan kesejahteraan mengacu pada hasil penelitian Probst, et al (Probst et al., 2011) dibentuk melalui 5 (lima) indikator yaitu peningkatan pengetahuan, peningkatan aksesibilitas, peningkatan partisipasi, peningkatan keragaman dan kualitas produk yang dibeli, peningkatan aset. Model pengukuran variabel keberdayaan di atas dapat dikonversi menjadi persamaan berikut:

$$
\begin{aligned}
\mathrm{Y} 21 & =\lambda 2.1 \eta 2+\varepsilon 21 \\
\mathrm{Y} 22 & =\lambda 2.2 \eta 2+\varepsilon 22 \\
\mathrm{Y} 23 & =\lambda 2.3 \eta 2+\varepsilon 23 \\
\mathrm{Y} 24 & =\lambda 2.4 \eta 2+\varepsilon 24 \\
\mathrm{Y} 25 & =\lambda 2.5 \eta 2+\varepsilon 25
\end{aligned}
$$

Keterangan :

$\eta 2=$ Kesejahteraan 
$\lambda=$ Hubungan antara variable laten terhadap indicator

Y21 = Peningkatan pengetahuan $/$ keterampilan

Y22 = Peningkatan aksesibilitas

Y23 = Peningkatan partisipasi

Y24 = Peningkatan keragaman dan kualitas produk yang dibeli

Y25 = Peningkatan aset

$\varepsilon \quad=$ Kesalahan pengukuran (measurement error).

Persamaan struktural (structural equations) dalam penelitian ini -yang dirumuskan untuk menyatakan hubungan kausalitas antar berbagai konstruk- dibangun dengan pedoman berikut ini.

$$
\begin{aligned}
& \mathrm{Y} 1=\beta 1 \mathrm{X} 1+\mathrm{z} 1 \ldots \ldots \ldots \ldots \ldots \ldots \\
& \mathrm{Y} 2=0,529 \beta 2 \mathrm{X} 1+\beta 3 \mathrm{Y} 1+\mathrm{z} 2 .
\end{aligned}
$$

Keterangan:

Y2 $=$ Kesejahteraan

Y1 = Modal Dasar Manusia

$\mathrm{X} 1=$ Pemberdayaan

X2 = Modal Dasar Manusia

$\mathrm{e}=$ Kesalahan pengukuran (measurement error).

\section{HASIL DAN PEMBAHASAN}

Kemiskinan erat hubungannya dengan modal manusia (human capital), jika modal manusia tersebut postif maka akan membawa kebahagiaan atau kekayaan tetapi jika sebaliknya modal manusia tersebut negatif maka akan membawa kemiskinan (Khan et al., 2016). Dengan seperti itu usaha nyata yang dapat diupayakan untuk mengurangi bahkan menghilangkan kemiskinan yaitu dengan merubah human capital negatif dari masyarakat menjadi human capital positif dari masyarakat tersebut. Human capital positif dapat dijadikan modal untuk memperbaiki kehidupan mereka di kemudian hari.

Untuk merubah human capital tersebut tentu akan sulit jika hanya menghandalkan pihak pemerintah sebagai penanggungjawab masyarakat yang di lingkungannya. Perlu melibatkan pihak lain atau memperdayakan masyarakat lain yang dengan dengan rela membantu merealisasikan perubahan tersebut. Pemberdayaan masyarakat dapat pula dilakukan dengan berbasis Zakat, dimana Strategi demikian disebut Strategi Societal Welfare (Nasrullah, 2018). Dalam studi ini mengukur kaitan antara modal dasar manusia, pemberdayaan masyarakat dan kesejahteraan masyarakat miskin.

Untuk mengukur human capital terdapat lima indikator yaitu tingkat pendidikan, tingkat kesehatan, jumlah tanggungan, pendapatan, dan kepemilikan asset. Kelima indikator tersebut dapat mengukur human capital yang ada. Dapat dibuktikan melalui tabel berikut: 
Jurnal Ekonomi \& Pendidikan, 17(1), 2020

Tabel 1. Koefisien Regression Weights dan Loading Factor Indikator Konstruk Modal Dasar Manusia

\begin{tabular}{llllllll}
\hline & & & RW & S.E. & C.R. & P & LF \\
\hline Y1.1 & $<---$ & Modal_Dasar_Manusia & 1.000 & & & & .341 \\
Y1.2 & $<---$ & Modal_Dasar_Manusia & 1.241 & .378 & 3.279 & .001 & .661 \\
Y1.3 & $<---$ & Modal_Dasar_Manusia & 1.839 & .559 & 3.288 & .001 & .682 \\
Y1.4 & $<---$ & Modal_Dasar_Manusia & 1.095 & .359 & 3.051 & .002 & .496 \\
Y1.5 & $<---$ & Modal_Dasar_Manusia & 1.068 & .357 & 2.995 & .003 & .471 \\
\hline
\end{tabular}

Berdasarkan kuesioner tersebut dapat mendiskripsikan human capital yang dimiliki responden penerima pemberdayaan LAZ dompet Dhuafa Yogyakarta. Hasil dari analisis deskriptif responden tersebut sebagai berikut:

Tabel 2 Kualitas Modal Dasar Manusia Yang Dimiliki

Responden Penerima Pemberdayaan LAZ Dompet Dhuafa Yogyakarta

\begin{tabular}{ccc}
\hline Variabel dan indikator & Skor & Tingkat Penilaian \\
\hline Modal dasar manusia Y1 & 2.3346 & Cukup Rendah \\
Tingkat Pendidikan & 2.4733 & Cukup Rendah \\
Tingkat kesehatan & 1.9933 & Rendah \\
Jumlah Tanggungan & 2.5267 & Cukup Rendah \\
Pendapatan & 2.5067 & Cukup Rendah \\
Pemilikan Aset & 2.1733 & Cukup Rendah \\
\hline
\end{tabular}

Dari tabel 2 tersebut, dapat disimpulkan bahwa human capital responden yang notabennya penerima pemberdayaan LAZ dompet Dhuafa Yogyakarta masih cukup rendah sehingga masih membutuhkan uluran tangan dari pihak lain.

Untuk mengukur pemberdayaan terdapat lima indikator yaitu penyadaran, pemahaman, pemanfaatan, dan penggunaan ketrampilan. Sedangkan indikator kesejahteraan memiliki indikator peningkatan pengetahuan/keterampilan, peningkatan aksesibilitas, peningkatan partisipasi, peningkatan keragaman dan kualitas produk yang dibeli, dan peningkatan asset. Indikator-indikator tersebut dapat mengukur seberapa besar tingkat pemberdayaan dan kesejahteraan pelaku pemberdayaan. Hasil dari analisis deskriptif responden pelaku pemberdayaan tersebut sebagai berikut: 
Tabel 3. Hasil Penilain (Skor) Terhadap Kualitas

Kemampuan Pelaku Pemberdayaan

\begin{tabular}{ccc}
\hline Indikator & Skor & Tingkat Penilaian \\
\hline Kemampuan pelaku pemberdayaan & 3,76 & Tinggi \\
Tingkat kemampuan kognisi & 3,70 & Tinggi \\
Tingkat kemampuan psikomotorik & 3,87 & Tinggi \\
Tingkat kemampuan afektif & 3,72 & Tinggi \\
\hline
\end{tabular}

Dari tabel 3 tersebut dapat dilihat bahwa pelaku pemberdayaan memiliki tingkat pemberdayaan dan kesejahteraan yang tinggi dilihat dari tingkat kemampuan kognisi, tingkat kemampuan psikomotorik, dan tingkat kemampuan afektifnya.

Untuk menguji hubungan dari beberapa variabel di atas, data yang digunakan adalah data tentang hubungan antar variabel sesuai dengan model struktural seperti disajikan pada Tabel 4 di bawah ini:

Tabel 4. Koefisien Regresi Hubungan antar konstruk Pemberdayaan Terhadap Modal Manusia Serta Kesejahteraan Rumah Tangga Miskin

\begin{tabular}{|c|c|c|c|c|}
\hline \multicolumn{3}{|c|}{ Variabel } & Estimate & Prob \\
\hline MODAL MANUSIA & $<---$ & PDAYA & .107 & .027 \\
\hline KSEJAHTERAAN & $<---$ & MODAL MANUSIA & .642 & .016 \\
\hline KSEJAHTERAAN & $<---$ & PDAYA & .581 & .013 \\
\hline
\end{tabular}

Berdasarkan tabel 4 di atas, dapat disimpulkan bahwa pemberdayaan berpengaruh positif signifikan terhadap modal manusia (koefisien regresi sebesar 0,107 dengan $p \leq 0,050$ ); pemberdayaan berpengaruh positif signifikan terhadap kesejahteraan (koefisien regresi sebesar 0,581 dengan $\mathrm{p} \leq 0,050)$; dan modal manusia berpengaruh positif signifikan terhadap kesejahteraan (koefisien regresi sebesar 0,642 dengan $\mathrm{p} \leq 0,050$ ). Koefisien pengaruh langsung antara dua variabel identik dengan koefisien regresi yang digunakan untuk pengujian hipotesis, sedangkan pengaruh tak langsung menunjukkan hubungan satu variabel eksogen dengan satu variabel endogen yang menjadi pusat perhatian akhir melalui satu variabel endogen lainnya sebagai variabel perantara. Sementara itu, pengaruh total menunjukkan pengaruh keseluruhan masing-masing variabel eksogen terhadap variabel endogen akhir, yang merupakan penjumlahan pengaruh langsung dan pengaruh tak langsung.

Keberhasilan seseorang atau kelompok tidak hanya ditentukan oleh modal fisik tetapi modal manusia seperti pendidikan dan kesehatan yang memadai serta kemampuan membangun jaringan antar sesama juga memegang peranan penting dalam keberhasilan keberdayaan suatu masyarakat. Terdapat korelasi dimana semakin tinggi proses pemberdayaan akan menciptakan keberdayaan masyarakat (Widjajanti, 2011). 
Pembangunan modal manusia melalui pendidikan merupakan determinan penting untuk menurunkan jumlah masyarakat miskin (Meidiana \& Marhaeni, 2019).

Tingkat pendidikan dan tingkat kesehatan responden tergolong rendah karena responden atau orang tua responden belum memahami bahwa pendidikan merupakan investasi masa depan, demikian pula dengan kesehatan. Di benak sebagian responden memahami bahwa pendidikan identik dengan mengeluarkan biaya yang cukup besar dan jika selesai belum tentu menjamin hidup yang lebih baik. Belum tentu mendapatkan pekerjaan. Biaya pendidikan yang semakin mahal dan kemampuan ekonomi yang rendah juga merupakan penyebab menurunnya keinginan responden untuk meningkatkan kemampuannya melalui pendidikan formal.

Sedangkan untuk kesehatan, kesehatan belum menjadi perhatian karena hampir sebagaian besar pendapatan responden digunakan untuk kebutuhan pokok dan bayar hutang sementara kelebihannya untuk acara-acara adat seperti sumbangan perkawinan atau tradisi-tradisi lainnya. Hasil penelitian memperlihatkan responden yang lulus SD berjumlah 34,7 persen; sisanya sudah mampu menamatkan pendidikan sampai tingkat SMP bahkan SMA. Data menunjukkan kebanyakan responden hanya lulusan SMP dimana persentasenya mancapai 46,7, sedangkan sisanya yaitu 18,7 persen berpendidikan SMA. Tidak ada responden yang berpendidikan lebih dari SMA. Pendidikan yang rendah diatas menyebabkan produktivitas responden sangat rendah, ini ditunjukkan dengan pendapatan yang rendah dengan jam kerja yang tinggi.

Kaitannya dengan proses pemberdayaan, responden yang memiliki tingkat pendidikan dan kesehatan yang lebih baik cenderung memiliki pengetahuan dan ketrampilan serta kemampuan membangun jaringan atau hubungan antar sesama yang lebih memadai, sehingga responden akan lebih berpartisipasi dalam kegiatan yang memiliki nilai positif terhadap kehidupannya. Partisipasi responden dalam proses pemberdayaan merupakan salah satu kunci keberhasilan dalam membentuk masyarakat berdaya dan mandiri, baik berdaya secara sosial, ekonomi maupun politik. Peningkatan kualitas modal dasar manusia masyarakat merupakan hal penting dalam menghadapi perkembangan teknologi dan informasi saat ini. Semua pihak harus memahami bahwa modal dasar manusia memiliki pengaruh terhadap keberhasilan dalam berusaha dan peningkatan pendapatan. Oleh karena itu pendidikan dan pelatihan menjadi faktor utama untuk meningkatkan pendapatan manusia disamping motivasi dan niat. Dilihat dari pengaruh langsung maupun tidak langsung, faktor yang paling kuat dalam menentukan terbentuknya keberdayaan ternyata bukan modal manusia.

\section{SIMPULAN}

Berdasarkan uraian di atas, maka dapat disimpulkan bahwa Kondisi modal dasar manusia masyarakat miskin penerima pemberdayaan LAZ Yogyakarta cukup rendah. Kondisi modal dasar manusia memiliki hubungan dan pengaruh positif dan nyata terhadap kesejahteraan. Kesejahteraan secara nyata dipengaruhi oleh modal dasar manusia. Rendahnya kesejahteraan 
dipengaruhi secara nyata oleh masih rendahnya modal munusia terutama terkait dengan tingkat pendidikan dan Kesehatan masyarakat yang masih rendah.

Proses pemberdayaan tergolong rendah. Proses pemberdayaan yang masih cukup rendah tersebut terutama karena belum optimalnya keterlibatan mayarakat dalam perencanaan, pengorganisasian dan evaluasi program pemberdayaan. Hal ini mengindikasikan bahwa dalam proses pemberdayaan, masyarakat miskin hanya dilibatkan sebagai pelaksanaan program saja. Pemberdayaan berpengaruh positif dan signifikan terhadap peningkatan modal manusia masyarakat miskin. Dengan kata lain kuat lemahnya upaya pemberdayaan menentukan kuat lemahnya tambahan modal manusia masyarakat miskin dan hal ini merupakan modal yang baik untuk mendorong terjadinya kesejahteraan. Tingkat kesejahteraan masyarakat miskin tergolong rendah. Rendahnya tingkat kesejahteraan dipengaruhi secara nyata oleh rendahnya proses pemberdayaan dan kurang tersedianya modal manusia. Rendahnya tingkat kesejahteraan juga disebabkan oleh rendahnya kemampuan kognitif, afektif dan psikomotorik yang merupakan akibat dari rendahnya kualitas sumberdaya manusia (modal manusia) yang dimiliki. Masyarakat miskin masih sukar memahami dan mengidentifikasi kebutuhan dan potensi yang dimiliki, serta masih sukar mencari dan memanfaatkan informasi dan peluang usaha baru.

Mengingat kualitas modal manusia yang cenderung rendah, maka diperlukan upaya penyediaan modal fisik yang lebih untuk masyarakat terutama sarana dan prasarana pendidikan, kesehatan dan ekonomi. Kegiatan penyuluhan, pelatihan, dan pendampingan dengan materi yang berhubungan dengan kebutuhan dan potensi, harus ajeg dan berkelanjutan agar kualitas modal manusia meningkat. Untuk meningkatan kesejahteraan maka diperlukan upaya memperbaiki proses pemberdayaan, meningkatkan kemampuan pelaku pemberdayaan dan menjamin ketersediaan modal manusia. Perbaikan proses pemberdayaan dapat dilakukan dengan meningkatkan keterlibatan masyarakat secara optimal.

\section{DAFTAR PUSTAKA}

Badan Pusat Statistik. (2019). Indikator Kesejahteraan Rakyat 2019. https://www.bps.go.id/publication/2019/11/28/27d78d49bc6aa22bd3672b59/indikatorkesejahteraan-rakyat-2019.html

Becker, G. S. (1995). Human Capital and Poverty Alleviation. In Human Resources Development and Operation Policy (pp. 1-17).

Fujikake, Y. (2008). Qualitative Evaluation: Evaluating People's Empowerment. Japanese Journal of Evaluation Studies, 8(2), 25-37. https://doi.org/10.11278/jjoes2001.8.2_25

Indonesia Investments. (2017). Kemiskinan di Indonesia. https://www.indonesiainvestments.com/id/keuangan/angka-ekonomi-makro/kemiskinan/item301? 
Khan, A. U., Iqbal, T., \& Rehman, Z. U. (2016). Impact of Human Capital on Poverty Alleviation in District Karak, Khyber Pakhtunkhwa. Dialogue (1819-6462), 11(2), 228-241. http://search.ebscohost.com/login.aspx?direct=true $\& d b=a 9 h \& A N=115450732 \&$ site $=$ ehostlive

Lingga, M. A. (2018). Kemiskinan Masih Jadi Tantangan Besar Indonesia. Kompas.Com. https://ekonomi.kompas.com/read/2018/10/25/154008526/kemiskinan-masih-jaditantangan-besar-indonesia

Meidiana, N. P. C. A. T., \& Marhaeni, A. A. I. N. (2019). Pengaruh Kepemilikan Aset, Ketersediaan Infrastruktur, Dan Pendidikan Terhadap Pendapatan Dan Kesejahteraan Rumah Tangga Miskin. Buletin Studi Ekonomi, $24(1), \quad 54$. https://doi.org/10.24843/bse.2019.v24.i01.p04

Nasrullah, N. (2018). Peran Strategis Amil Zakat dalam Memastikan Efektifitas Ibadah Zakat yang Berorientasi Kesejahteraan Sosial. AL-MUQAYYAD: Jurnal Ekonomi Syariah, 1(1), 110130. https://doi.org/10.46963/jam.v1i1.53

Nurudin, M., Mara, M. N., \& Kusnandar, D. (2014). Ukuran sampel dan distribusi sampling dari beberapa variabel random kontinu. 03(1), 1-6.

Probst, J. C., Bellinger, J. D., Walsemann, K. M., Hardin, J., \& Glover, S. H. (2011). Higher risk of death in rural blacks and whites than urbanites is related to lower incomes, education, and health $\quad$ Health Affairs, 30(10), 1872-1879. https://doi.org/10.1377/hlthaff.2011.0668

Situmorang, A. P. (2020). Gini Ratio Indonesia September 2019 Turun Tipis Menjadi 0,380. https://www.merdeka.com/uang/gini-ratio-indonesia-september-2019-turun-tipis-menjadi0380.html

Solikatun, Supono, \& Masruroh, Y. (2014). Kemiskinan Dalam Pembangunan. Jurnal Analisa Sosiologi, 3(1), 70-90. https://doi.org/10.20961/jas.v3i1.17450

Tilak, J. B. G. (2002). Education and Poverty. Journal of Human Development, 3(2), 191-207. https://doi.org/10.1080/14649880220147301

Todaro, M. P. (2000). Pembangunan ekonomi di dunia ketiga (1st ed.). Erlangga.

Widjajanti, K. (2011). Jurnal Ekonomi Pembangunan Model pemberdayaan masyarakat. Jurnal Ekonomi Pembangunan, 12(1), 15-27. 
Widyastuti, A. Y. (2018). Rasio Gini Masih Tinggi, JK: Negara Lain Juga Menghadapinya. Tempo.Co. https://bisnis.tempo.co/read/1156343/rasio-gini-masih-tinggi-jk-negara-lain-jugamenghadapinya

World Bank. (2000). World Attacking Development (Issue September). 